\title{
Help Me Help You! Using Online Discussions to Improve Student Success
}

\author{
Velvet Weems-Landingham \\ Kent State University
}

\author{
Judy Paternite \\ Kent State University
}

\begin{abstract}
Although online coursework is now considered commonplace, instructors still struggle to forge online student engagement critical to success. Beyond course design and instructor quality, student-instructor interactions are the strongest predictors of online learning and success (Eom and Ashill, 2016). This 90minute experiential exercise describes how asynchronous online discussions, referred to as check-ins, can be used to help instructors forge connections and promote success. Three check-ins - touchpoints at the beginning, middle, and end of the grading period - are outlined as an approach to proactively engaging online students. These check-ins enable instructors to affirm presence and open dialogue with students, understand their unique circumstances, gather useful first-hand information, and provide additional supports which foster success. This exercise provides templates for designing and implementing online asynchronous discussions to help address student needs. It is of value to online instructors and administrators hoping to improve online student engagement, outcomes, evaluations of instruction, and teaching effectiveness.
\end{abstract}

Keywords: online discussions, student engagement, check-ins

\section{INTRODUCTION}

There is a monumental movement in higher education toward online coursework (Allen, Seaman, Poulin, \& Straut, 2016; Van Rooij \& Zirkle, 2016). Nearly 90 percent of four-year public colleges and universities offer online courses (Parker, Lenhart, \& Moore, 2013). More than 6.4 million students take at least one online course each year (Seaman, Allen, \& Seam, 2018). These numbers will become even more prolific as the need for social distancing increases. Although online student numbers have and will continue to climb steadily, the same cannot be said of their success (Allen \& Seaman, 2013; Eom \& Arbaugh, 2011). A closer look at online student experiences suggests that emphasis on data delivery, to the neglect of empathetic engagement, may attribute to this problem (Natale \& Libertella, 2016; Eom \& Ashill, 2016). Researchers have found that student-to-instructor interactions foster relatedness (e.g. feelings of connectedness) and have the greatest impact on student perceptions of satisfaction and overall success (Buntz \& Substinky, 2017). Resultantly, facilitating interactions within the online classroom could prove key to enhancing student satisfaction and success. 


\section{THEORETICAL FRAMEWORK/TEACHING IMPLICATIONS}

Eom and Ashill (2016) found that beyond course design, instructor quality and student-instructor interactions are the strongest predictors of online learning and success. For those prepared to teach online, greater levels of student interaction and, ultimately, performance can be achieved through the design and implementation of effective threaded discussions (LaPoint \& Guanwardena, 2004). This article outlines a three-phased approach to enhancing online student engagement using asynchronous threaded discussions: check-ins. These instructor-initiated touchpoints staged at the beginning, middle, and end of the group life cycle helps instructors affirm online presence (Panteli, 2004), clarify course and performance expectations, monitor performance, provide added supports, and enable a more holistic evaluation of teaching and learning outcomes. Combined, this process enables real-time feedback so that instructors can help online students succeed. This 90-minute activity offers learning objectives, guidance for designing and implementing check-ins, and acknowledgement of challenges and adaptations.

\section{Learning Objectives}

- Understand check-ins as a tool for connecting with online students

- Examine check-ins as touchpoints within the online group life cycle

- Construct check-in content and determine implementation strategies

- Explore check-in challenges and adaptations

\section{EXERCISE OVERVIEW}

Most online instructors have likely grappled with various tools in hopes of achieving meaningful connections with their online students. Discussion threads offer one of the simplest, most accepted, and widely used methods for doing so. Asynchronous discussions, available online free of charge and standard with most Learning Management Systems, provide instructors and students with a relatively open forum for talking and exchanging ideas. What the instructor may not realize is the power discussions have to foster student-instructor interactions and forge connections critical to success. Asynchronous instructor-initiated discussions (check-ins) enable instructors to establish touchpoints within the course and connect regardless of time or physical proximity, can be integrated to a multitude of contexts, and serve as an optimal tool for facilitating student-instructor interactions.

In accordance with theory on group development (Tuckman, 1977; Gersick, 1988), check-ins should be designed and implemented to "touch" students at three distinct times during the course life cycle: beginning, middle, and end. The beginning, or forming stage, represents the phase when students experience heightened anxiety and uncertainty. Thus, content should focus on affirming presence, establishing trust, clarifying expectations, and highlighting existing supports. Throughout the course, the instructor should communicate routinely to assist online students in maneuvering difficulties and establishing norms of performance. The middle represents the time in which students' focus transitions to emphasize work completion. Consequently, this check-in should help students assess their performance and provide additional supports to achieve their objectives. The final check-in represents the adjourning stage. Now that the work is done, this ending check-in enables students to reflect upon their online experiences and evaluate performances and outcomes.

Check-ins should be constructed to convey and collect information. Static content advances shared knowledge deemed important to student success, while open-ended questions allow for the collection and processing of real-time information. Appendix A offers some general questions to aid in crafting check-in content. Appendices B-D provide worksheets and examples for crafting beginning, middle, and ending check-ins. Each check-in should begin with a brief greeting and end with a concise statement on how students can access additional support. Actions deemed important for students to complete will determine what information or knowledge is needed and how it will be integrated online. Finally, open-ended questions should be incorporated to determine if additional interventions are needed. 
Check-ins should be implemented to maximize responsiveness. The authors suggest making threads viewable, gradable, and timebound. The ability to read and respond to student posts fosters transparency with the ability to enhance student-to-instructor and peer relatedness. Making posts gradable (2-5\%) increases the probability of completion. Grading comments allow instructors to offer general supports, craft private responses, address overarching issues, and establish leadership and trust. Finally, making check-ins timebound creates a snapshot, ensuring that captured information is relevant and applicable to the here and now. When effectively implemented as graded interactive timebound deliverables, check-ins will allow the instructor to gauge the pulse of the course and create opportunities for interaction which help acclimate students, offer supports, and inspire performance.

Once check-ins close, the instructor will want to spend time processing feedback, making necessary course modifications, and communicating findings. They should reflect on the data and consider modifications which will serve students' needs. With this added clarity, expectations can be refined, perceptions managed, and strategies for improving performance developed. To complete the check-in process, any discoveries and potential changes should be agreed upon and clearly communicated. The following sections provide instructions on crafting content for beginning, middle, and ending check-ins.

\section{Check-In01: Beginning}

The beginning of the grading period is often challenging for online students (Broadbent \& Poon, 2015). Hence, time should be set aside for students to acclimate and develop their unique approach to the coursework. Initial work should focus largely on activities that promote clarity and connection with lesser emphasis on subject matter expertise. The initial check-in should be designed to ensure students are present and available, are able to read and understand the syllabus, review varied supports, and understand how to get help when they need it. (See Appendix B: Check-in01 for the planning worksheet and example).

The initial check-in should be made available during the first two weeks of the grading period to help onboard students. This practice gives the instructor an accurate snapshot of how they are doing and allows you to set the tone for the course. If students seem distressed, the instructor can establish a call or virtual meeting to clarify any concerns. A re-cap discussion post can be included to reiterate solutions to confusing points and offer additional information students might need.

\section{Check-In02: Middle}

The middle of the grading period marks the time in which online course norms have been established and students experience a heightened need to perform (Gersick, 1988). During this performance phase, students develop an acute awareness of time, deadlines, and the need to ramp up their efforts. The climate of this phase is best described as open, communicative, cooperative, and empathetic. Check-in02 (see Appendix C) provides an opportunity for the instructor to dialog with students and develop consensus on actions needed to achieve successful. For students, this means understanding their current standing, what work remains, and how to achieve their individualized performance goals. From here, they can articulate what supports they require to achieve their desired outcome. For the instructor, this includes reviewing evaluative criteria (self- or other-imposed), gathering student perceptions regarding performance, and implementing approaches to enhance perceived teaching and student performance outcomes. Processing this information provides strategies for enhancing online courses to meet student needs.

The midpoint check-in should take place before mid-term grades are due. Check-in02 allows you to gauge how well students are doing and make any necessary course corrections while adequate time remains. As always, once the check-in has been completed, the instructor should report findings along with any course corrections to students as confirmation that their voices have been heard.

\section{Check-In03: End}

The end of the grading period is a time to reflect upon the online learning experience, using any number of appreciative questions. Tuckman (1977) refers to this stage of group development as adjourning. Prompting students to check in at the end of the grading period allows them to achieve closure and end on a positive note. The contents of this check-in should assist members in reflecting upon their online 
experiences, review learning objectives and outcomes, and identify remaining work. Thus, it might be important to recap learning objectives, solicit constructive feedback, and summarize grading and evaluative criteria. Ending reflections will ensure a more holistic assessment of the online teaching and learning experience.

Check-in03 (see Appendix D) should take an appreciative stance, asking open-ended questions that provide an opportunity to reflect upon student experiences beyond "the grade." This helps students capture the fullness of their experiences: relatedness, learning, and personal development. This is a time for recognizing what students have accomplished and how far they have come since the beginning of the grading period. Check-in03 provides a platform for gaining clarity on what was accomplished. For students, this means reviewing what they learned about the subject matter, why it is important, and how it can be taken forward to other arenas. This procedure will allow them to ascertain the value gained from their time spent online. For the instructor, this includes reflecting on inputs provided by students in order to improve expectations and performances in a future course. This is critical for tweaking the course while the experiences are fresh.

\section{CHALLENGES AND ADAPTATIONS}

By far, most students embraced the check-in process. Many expressed their appreciation for the opportunity to have access to additional support.

As with any online course, one of the biggest challenges is getting students to participate. Assigning points for each discussion thread helps encourage participation. Underperforming students may need to be addressed through email, since they may not want to divulge to the class that they have fallen behind.

Another challenge is the ability to adjust the course halfway through the semester. Time will need to be set aside to process and respond to information gained from each check-in. Establish a journal of items to change in the course now and in the future. There may be small changes such as providing additional resources or altering due dates, but major changes will need to be completed in time for the next semester's class. Acknowledging the students' comments for improvements will help appease them if adjustments cannot be made in the current semester. After the semester, process student evaluations to determine areas of teaching improvement and outline needed adjustments.

Developing content in the middle of the semester can be time consuming. Enlist preexisting resources (e.g. YouTube, Lynda, etc.) Use best practices from other colleagues and use prior courses to develop FAQs.

Check-in adaptations will be needed, depending on the course, audience, and other considerations. Check-ins can be modified regardless of grading period duration. Content can be changed and updated as needed - based upon the audience - and they can be revised to improve responsiveness. Additional checkins can be added to address particular requirements. As a result of student input, syllabus and existing supports may need to be modified.

\section{CONCLUSION}

Although recent changes to the evaluation of teaching have improved instructors' abilities to capture usable information, this process remains reactive and alone does not allow for real-time corrective action to foster online student success. Check-ins, student touchpoints staged strategically throughout the life cycle of the course, help instructors forge more substantive connections with students, gather constructive firsthand information, assess achievement of course objectives, and provide supports to enhance performance by all. When instructors and students actively and sincerely engage in this process, interactions connect students to their instructor which can help improve online student satisfaction and performance. 


\section{REFERENCES}

Allen, E.I., \& Seaman, J. (2013). Changing Course: Ten Years of Tracking Online Education in the United States. Sloan Consortium. PO Box 1238, Newburyport, MA 01950.

Allen, I.A., Seaman, J., Poulin, R., \& Straut, T.T. (2016). Online report card: Tracking online education in the United States. Babson Park, MA: Babson Survey Research Group Quahog Research Group. Retrieved from http://onlinelearningconsortium.org/read/online-report-card-tracking-onlineeducation-united-states-2015/

Broadbent, J., \& Poon, W. (2015). Self-regulated learning strategies \& academic achievement in online higher education learning environments: A systematic review. The Internet and Higher Education, 27, 1-13. doi:10.1016/j.iheduc.2015.04.00

Butz, N.T., \& Stupnisky, R.H. (2017). Improving student relatedness through an online discussion intervention: The application of self-determination theory in synchronous hybrid programs. Computers \& Education, 114(2017), 117-138.

Daspit, J.J., Mims, T.C., \& Zavattaro, S.M. (2015). The role of positive psychological state in online learning: Integrating psychological capital into the Community of Inquiry framework. Journal of Management Education, 39, 626-649.

Eom, S.B., \& Arbaugh, J.B. (Eds.). (2011). Student satisfaction and learning outcomes in e-learning: An introduction to empirical research. Hersey, PA: Information Science Reference.

Eom, S.B., \& Ashill, N. (2016). The determinants of students' perceived learning outcomes and satisfaction in university online education: An update. Decision Sciences Journal of Innovative Education, 14(2), 185-215.

Gersick, C.J.G (1988). Time and transition in work teams: Toward a new model of group development. Academy of Management Journal, 11, 67-80.

Hwang, A. (2018). Online and Hybrid Learning. Journal of Management Education, 42(4), 557-563.

Ivancevich, J.M., Gilbert, J.A., \& Konopaske, R. (2009). Studying and Facilitating Dialogue in Select Online Management Courses. Journal of Management Education, 33(2), 196-218.

LaPoint, D., \& Guanwardena, C. (2004). Developing, testing and refining of a model to understand the relationship between peer interaction and learning outcomes in computer-mediated conferencing. Distance Education, 25, 83-106.

Natale, S.M., \& Libertella, A.F. (2016). Online Education: Values Dilemma in Business and the Search for Empathic Engagement. Journal of Business Ethics, 138, 175-184.

Panteli, N. (2004). Discursive Articulations of Presence in Virtual Organizing. Information and Organization, 14, 59-81. doi:10.1016/j.infoandorg.2003.10.001

Parker, K., Lenhart, A., \& Moore, K. (2013). The Digital Revolution and Higher Education: College Presidents, Public Differ on Value of Online Learning. Pew Internet \& American Life Project.

Seaman, J.E., Allen, I.E., \& Seaman, J. (2018). Grade increase: Tracking distance education in the United States. Babson Park, MA: Babson Survey Research Group.

Stickney, L.T., Bento, R.F., Aggarwal, A., \& Adlakha, V. (2019). Online Higher Education: Faculty Satisfaction and Its Antecedents. Journal of Management Education, 43(5), 509-542.

Tuckman, B.W., \& Jensen, M.A.C. (1977). Stages of Small-Group Development Revisited. Group and Organization Studies, 2(4), 419-27.

Van Rooij, S.W., \& Zirkle, K. (2016). Balancing pedagogy, student readiness and accessibility: A case study in collaborative online course development. Internet and Higher Education, 28, 1-7. 


\section{APPENDIX A: DESIGN}

As you design the check-ins for each phase of the course, you will need to ensure content and information is available for the students. The following are questions which will aid in updating content and crafting check-ins during each phase of the process.

- Where should the students be in their online course? (e.g. What deliverables should have been completed? What percentage of work has been done? What should they know? What chapters have they read?)

- What is the most impactful (re: student success) information they should have at this stage?

- How will you ensure they have acquired this information?

- Is it important to affirm this knowledge? If so, how will you accomplish this?

- What are alternative approaches to ensure they have this information?

- What will you do if they do not know or understand key information?

- How will you communicate better or differently?

- What are your markers for success?

- How have you determined these markers? Have the students met these markers? If not, how can you help them?

- Are the markers clearly defined? What methods of communication have you enlisted?

- What if the students define success differently?

- What will you do if the markers have not been met?

- How can you modify the course to help students be successful?

- What questions should you ask to get the information you need to help those students who are struggling? What static information or course changes might prove useful during this phase?

- What findings might result from this check-in? How will you consolidate and communicate the findings?

- Review past evaluations of instruction. What instructor performance metrics (institutionspecific or otherwise) should you include to monitor and improve upon your teaching performance? What additional questions should you ask to determine the best ways to assist your students? 


\section{APPENDIX B: CHECK-IN01}

Provide a greeting (2-3 sentences) for students as they begin their check-in process.

Provide a conclusion (2-3 sentences) on how to access additional help/support.

Indicate (5) actions students must take in order to start out successfully.

\begin{tabular}{|l|l|}
\hline & On-boarding Actions \\
\hline 1. & \\
\hline 2. & \\
\hline 3. & \\
\hline 4. & \\
\hline 5. & \\
\hline
\end{tabular}

Describe the knowledge/information needed to complete each action (if each exists \& where).

\begin{tabular}{|l|l|l|}
\hline & Exist & Knowledge/Information \& Integration* \\
\hline 1. & Y/N & \\
\hline 2. & Y/N & \\
\hline 3. & Y/N & \\
\hline 4. & Y/N & \\
\hline 5 & Y/N & \\
\hline
\end{tabular}

*Text, Hyperlink, Poll/Survey, Video, Etc.

Specify 2-3 questions which will confirm that students have begun successfully.

\begin{tabular}{|l|l|}
\hline & Questions \\
\hline 1. & \\
\hline 2. & \\
\hline 3. & \\
\hline
\end{tabular}




\section{Check-In01 Example}

Onboarding Greeting: Welcome to Business 101 online. In order to ensure a successful on-boarding experience, check-in01 offers a review of information you need to get started.

Conclusion: Please be sure to contact me if you have questions or concerns. As always, please post questions \& comments to our Student Forum.

Indicate (5) actions students must take in order to start out successfully.

\begin{tabular}{|c|l|}
\hline & On-boarding Actions \\
\hline 1. & Logon \& complete the site tour \\
\hline 2. & Review the syllabus \& take the syllabus test \\
\hline 3. & Understand how to get help \\
\hline 4. & Review course deliverables \& points \\
\hline 5. & Post any questions to the student forum \\
\hline
\end{tabular}

Describe the knowledge/information needed to complete each action (include integration).

\begin{tabular}{|l|l|l|}
\hline & Exist & Knowledge/Information \& Integration \\
\hline 1. & $\mathrm{Y}$ & $\begin{array}{l}\text { Logon \& Site Tour } \\
\text { Logon instructions emailed as part of the welcome message also posted as an announcement } \\
\text { for the course. Site tour recorded and posted as a link to the site. }\end{array}$ \\
\hline 2. & $\mathrm{Y}$ & $\begin{array}{l}\text { Syllabus \& Syllabus Test } \\
\text { Students will be directed, as part of the orientation, to review the syllabus and link will be } \\
\text { provided to complete the syllabus test. Only those who pass the syllabus at 80\% will be } \\
\text { allowed access to the course. Students should be given an option to attend office hours or } \\
\text { chat if they cannot earn beyond 80\%. (unlimited \# of attempts allowed) }\end{array}$ \\
\hline 3. & $\mathrm{~N}$ & $\begin{array}{l}\text { Getting Help FAQ } \\
\text { This information is part of the syllabus. However, for emphasis I should develop a separate } \\
\text { hyperlink with best ways to get help (FAQ) }\end{array}$ \\
\hline 4. & $\mathrm{~N}$ & $\begin{array}{l}\text { Deliverables } \\
\text { Record lecture slides discussing each course deliverable. Slides should contain a hyperlink } \\
\text { so that students can post additional questions. }\end{array}$ \\
\hline 5 & $\mathrm{Y}$ & $\begin{array}{l}\text { Student Forum } \\
\text { Student Forum (discussion thread) is the central place where students can discuss questions } \\
\text { and concerns with their peers. I will monitor this thread and provide responses to } \\
\text { questions/concerns that go unaddressed. }\end{array}$ \\
\hline
\end{tabular}

Specify 2-3 questions which will confirm that students have begun successfully.

\begin{tabular}{|l|l|}
\hline & Questions \\
\hline 1. & Have you introduced yourself in our student forum? \\
\hline 2. & Have you completed the syllabus test and reviewed your test results? \\
\hline 3. & Do you have any questions or concerns at this time? \\
\hline
\end{tabular}




\section{APPENDIX C: CHECK-IN02}

Provide a greeting (2-3 sentences) for students as they begin to focus more heavily on performance.

Provide a conclusion (2-3 sentences) on how to access additional help/support.

Indicate (5) actions students must take in order to assess their standing \& improve performance.

\begin{tabular}{|l|l|}
\hline & Performance Actions \\
\hline 1. & \\
\hline 2. & \\
\hline 3. & \\
\hline 4. & \\
\hline 5. & \\
\hline
\end{tabular}

Describe the knowledge/information needed to complete each action (if each exists \& where).

\begin{tabular}{|l|l|l|}
\hline & Exist & Knowledge/Information \& Integration* \\
\hline 1. & Y/N & \\
\hline 2. & Y/N & \\
\hline 3. & Y/N & \\
\hline 4. & Y/N & \\
\hline 5 & Y/N & \\
\hline
\end{tabular}

*Text, Hyperlink, Poll/Survey, Video, Etc.

Specify 2-3 questions which will confirm that students understand standing and work remaining.

\begin{tabular}{|l|l|}
\hline & Questions \\
\hline 1. & \\
\hline 2. & \\
\hline 3. & \\
\hline
\end{tabular}




\section{Check-In02 Example}

Performance Greeting: Thank you for the diligence with which you have been working online. I know this work can be challenging, but remember it is equally rewarding. In order to ensure that you are progressing, check-in02 offers a review of information you need to determine your standing and improve upon performance.

Conclusion: Please be sure to contact me (hyperlink) if you have questions or concerns. As always, you can post questions \& comments to our Student Forum.

Indicate (5) actions students must take in order to assess their standing \& improve performance.

\begin{tabular}{|c|l|}
\hline & Performance Actions \\
\hline 1. & Review current grades and feedback \\
\hline 2. & Tally percentage of work currently done \\
\hline 3. & Understand the percentage of work remaining \\
\hline 4. & Understand where the struggles reside \\
\hline 5. & Devise the best approach for improvement \\
\hline
\end{tabular}

Describe the knowledge/information needed to complete each action (if each exists \& where).

\begin{tabular}{|c|l|l|}
\hline & Exist & Knowledge/Information \& Integration* \\
\hline 1. & Y/N & $\begin{array}{l}\text { Review syllabus (video-based) and show how to access feedback. YouTube videos work } \\
\text { for Bb Learn. Include verbiage from syllabus on how to contact professor for feedback. }\end{array}$ \\
\hline 2. & Y/N & $\begin{array}{l}\text { Video-based review and discussion of how to tally grades. Email all students that fall } \\
\text { below predetermined threshold (e.g. 70\%). }\end{array}$ \\
\hline 3. & Y/N & $\begin{array}{l}\text { Communicate, in body of check-in, percentage of work remaining. Link this to a table } \\
\text { which outlines the percentage of work remaining for each week. }\end{array}$ \\
\hline 4. & Y/N & $\begin{array}{l}\text { Share common performance issues and how to avoid them. Have students review due dates } \\
\text { to confirm understanding on when things are due and any implications. }\end{array}$ \\
\hline 5 & Y/N & $\begin{array}{l}\text { Highlight deliverables that have the greatest impact to performance. Discuss grading scale } \\
\text { and evaluative criteria. }\end{array}$ \\
\hline
\end{tabular}

*Text, Hyperlink, Poll/Survey, Video, Etc.

Specify 2-3 questions which will confirm that students understand standing and work remaining.

\begin{tabular}{|l|l|}
\hline 1. & $\begin{array}{l}\text { After a self-assessment of your performance, what are your greatest areas of struggle and how do } \\
\text { you plan to improve? }\end{array}$ \\
\hline 2. & If there are problem areas, how will you plan to improve your performance? \\
\hline 3. & How can I assist you in your success? \\
\hline
\end{tabular}




\section{APPENDIX D: CHECK-IN03}

Provide a greeting (2-3 sentences) for students as they reflect upon their online course experience.

Provide a thank you statement (2-3 sentences), including what you hope they learned and how it will be useful to them in the future.

Indicate (5) actions students must take in order to reflect upon their online course experience.

\begin{tabular}{|l|l|}
\hline & Reflective Actions \\
\hline 1. & \\
\hline 2. & \\
\hline 3. & \\
\hline 4. & \\
\hline 5. & \\
\hline
\end{tabular}

Describe the knowledge/information needed to complete each action (if each exists \& where).

\begin{tabular}{|l|l|l|}
\hline & Exist & Knowledge/Information \& Integration* \\
\hline 1. & Y/N & \\
\hline 2. & Y/N & \\
\hline 3. & Y/N & \\
\hline 4. & Y/N & \\
\hline 5 & Y/N & \\
\hline
\end{tabular}

*Text, Hyperlink, Poll/Survey, Video, Etc.

Specify 2-3 questions which will help the students reflect upon their experiences.

\begin{tabular}{|l|l|}
\hline & Questions \\
\hline 1. & \\
\hline 2. & \\
\hline 3. & \\
\hline
\end{tabular}




\section{Check-In03 Example}

Reflection Greeting: We are at the end of our Business 101 Online course. I'd like to thank you for the time you have invested and sincerely hope this was a positive learning experience for you. In concluding, I ask that you take some time to reflect upon your online experiences to close out our time together.

Conclusion: Please be sure to contact me (hyperlink) if you have questions or concerns. As always, you can post questions \& comments to our Student Forum.

Indicate (5) actions students must take in order to assess their standing \& improve performance.

\begin{tabular}{|c|l|}
\hline & Reflective Actions \\
\hline 1. & Recap learning objectives and course take-aways \\
\hline 2. & Discuss how the final grade will be calculated and posted \\
\hline 3. & Connect content to career aspirations \\
\hline 4. & Share next steps to consider \\
\hline 5. & Offer opportunities for continued connection \\
\hline
\end{tabular}

Describe the knowledge/information needed to complete each action (if each exists \& where).

\begin{tabular}{|l|l|l|}
\hline & Exist & Knowledge/Information \& Integration* \\
\hline 1. & Y/N & $\begin{array}{l}\text { Review learning objectives that students should have mastered and how they will be } \\
\text { helpful in their career endeavors, including knowledge, skill, and ability gained. }\end{array}$ \\
\hline 2. & Y/N & $\begin{array}{l}\text { Review how final grades will be calculated and where to find them. Reference university } \\
\text { policy regarding grading. }\end{array}$ \\
\hline 3. & Y/N & Share links to career data related to the area of study. \\
\hline 4. & Y/N & $\begin{array}{l}\text { Offer suggestions on what might come next for students. Include information on contacting } \\
\text { their advisor. }\end{array}$ \\
\hline 5 & Y/N & Offer ways in which students can stay in touch. Be a reference, if possible. \\
\hline
\end{tabular}

*Text, Hyperlink, Poll/Survey, Video, Etc.

Specify 2-3 questions which will confirm that students understand standing and work remaining.

\begin{tabular}{|c|l|}
\hline & Questions \\
\hline 1. & How did your behaviors, positive and negative, impact your learning experience? \\
\hline 2. & Summarize what you have learned as part of this course. \\
\hline 3. & Would you suggest this course to a friend: why or why not? \\
\hline
\end{tabular}

